\title{
O CASO EDVAN LIMA E A CORPOREIDADE DE PESSOAS EM SITUAÇÃO DE RUA EM CASOS DE VIOLÊNCIA: ANÁLISE DE DADOS DO JORNAL CORREIOWEB ${ }^{l}$
}

\author{
INGRID DA SILVA RAMALHO* \\ VIVIANE DE MELO RESENDE**
}

\begin{abstract}
RESUMO: Este trabalho faz parte da pesquisa Representação midiática da violação de direitos e da violência contra pessoas em situação de rua no jornalismo on-line e visa investigar a representação de Edvan Lima em textos publicados no Correioweb no ano de 2013, utilizando como base teórico-metodológica a análise de discurso crítica aliada a reflexões acerca da corporeidade na contemporaneidade. O recorte escolhido justifica-se por textos acerca do caso de Edvan Lima apresentarem características discursivas bem particulares, se comparadas às outras notícias e reportagens do corpus de 166 textos do Correioweb analisados na primeira fase da mesma pesquisa de que este artigo é recorte.
\end{abstract}

Palavras-chave: Análise de discurso crítica, situação de rua, corporeidade, Correioweb.

\begin{abstract}
This paper is part of the second fase of the research Media representation of violation of rigths and violence against homeless people in online journalism and intends to investigate the representation of Edvan Lima in texts published in Correioweb in 2013, based upon critical discourse analysis and reflexions about corporeality in the contemporaneity. The clipping chosen is justified since texts about the case of Edvan Lima present peculiar discursive characteristics if compared to other news of the 166 texts corpus from Correioweb analyzed in the first part of the research.
\end{abstract}

Keywords: critical discourse analysis; homeleessness; corporeality, Correioweb.

\section{INTRODUÇÃO}

Neste artigo, analisamos matérias publicadas na plataforma virtual do Correio Braziliense que abordam o assassinato de Edvan Lima em Brasília em 2013. Em etapa anterior da pesquisa de que este artigo é recorte, 166 textos publicados entre 2011 e 2013 que apresentaram resultados na busca por palavras-chave associadas à

*Universidade de Brasília UNB, Brasilia DF, Brasil. ingrid.s.ramalho@gmail.com

** Universidade de Brasília UNB, Brasilia DF, Brasil. resende.v.melo@gmail.com

${ }^{1}$ Agradecemos ao Conselho Nacional de Desenvolvimento Científico e Tecnológico (CNPq) a concessão de bolsas de estudo para o projeto de que este artigo é recorte e à Fundação de Apoio à Pesquisa do Distrito Federal (FAP-DF) o subsídio financeiro para apresentação de versão anterior deste trabalho no XII Congresso da ALED, em 2017, em Santiago do Chile. Agradecemos também a Carolina Araújo pela orientação com o uso do software NVivo e a Mariana Moura, Lygia Vaz, Daniele Mendonça e Dara Abreu pelas preciosas discussões sobre os dados e usos do software. 
situação de rua foram organizados no software NVivo e analisados com categorias teoricamente motivadas pela análise de discurso crítica, como intertextualidade e fontes jornalísticas, modos de referência, modos de avaliação e modos de representação (RESENDE; RAMALHO, 2017).

Por meio de matrizes de codificação facilitadas pelo software, foi possível chegar a alguns resultados relevantes em uma macro análise: (1) moradores/as e trabalhadores/as locais são os atores sociais que mais avaliam pessoas em situação de rua quando as matérias jornalísticas do corpus tem como tema a violência; (2) os qualificadores mais atribuídos a essa população nos 95 textos sobre população em situação de rua tematizando violência são respectivamente incômodas, perigosas e oportunistas; em contrapartida, qualificadores positivos aparecem de forma menos densa nesse contexto e são restritos a apenas três textos. Observando de forma mais atenta as ocorrências de qualificadores positivos, foi possível constatar que dois desses três textos se referem a um mesmo caso: o caso de Edvan Lima.

Por isso, decidimos analisar os textos que tratam do caso de Edvan Lima em microanálise pela ótica da análise de discurso crítica (ADC), já que essa perspectiva, aliada a estudos do campo das ciências sociais, constitui-se como arcabouço teórico-metodológico apropriado para a análise de questões sociais discursivamente manifestas.

Na primeira seção, contextualizamos a situação de rua em Brasília e no jornal Correio Braziliense, com base na primeira etapa analítica antes mencionada. $\mathrm{Na}$ segunda, focalizamos o caso de Edvan Lima e a similaridade entre este e outros casos brutais que ocorreram na capital federal e tiveram o uso do fogo como instrumento de ataque a pessoas em situação de rua. Na terceira seção, abordamos conceitos da $\mathrm{ADC}$ e da corporeidade na contemporaneidade, fundamentais para a investigação da representação de Edvan Lima nos textos em foco neste artigo, para, na quarta seção, analisarmos os dados.

\section{SITUAÇÃO DE RUA EM BRASÍLIA E NO CORREIO BRAZILIENSE}

O crescimento da população em situação de rua nas cidades está intrinsicamente ligado às reestruturações sociais advindas do sistema de produção capitalista, como discute Silva (2006). Se, em outras épocas, grupos caracterizados pela estadia em logradouros públicos e pela ausência de moradia convencional regular foram enquadrados como 'andarilhos', 'viajantes', 'exilados' ou 'doentes mentais' (PEREIRA, 2009), nos dados coletados no Correioweb datados de 2011 a 2013, pessoas pertencentes a esse grupo são normalmente referidas como 'moradores/ as de rua' e 'mendigos/as'; o primeiro termo é marcado pela naturalização da situação de rua como estado permanente, e o segundo carrega alto teor pejorativo, como discutimos em trabalho anterior (RESENDE; RAMALHO, 2017).

De acordo com Gatti e Pereira (2011), a população em situação de rua no Brasil tornou-se mais visível no final do século XIX, com o processo de modernização e urbanização propulsionado por medidas governamentais e grupos empresariais com apoio da elite e dos meios de comunicação. O crescimento dessa 
população foi perceptível na medida em que o desenvolvimento capitalista foi se instalando no país.

Diferente do que ocorre em outras capitais brasileiras - Porto Alegre, São Paulo, Belo Horizonte e Recife, por exemplo - onde a população em situação de rua está localizada em pontos de grande visibilidade e movimentação -, em Brasília essa população procura permanecer escondida dos olhares urbanos "para não ser expulsa em direção às cidades satélites da Capital e ao entorno do Distrito Federal ou, no caso de migrantes, às suas cidades de origem”" (PEREIRA, 2009, p. 93).

Os conflitos provenientes da coexistência de atores sociais em condições socioeconômicas e com interesses distintos ocupando o mesmo espaço urbano ganham ainda mais força em Brasília, pois além de atualmente exibir o maior Índice de Desenvolvimento Humano Municipal do Brasil $(0,824)$, segundo dados do Instituto Brasileiro de Geografia e Estatística (2010), ${ }^{2}$ a dinâmica da cidade distancia aglomerações populares do centro urbano. Brasília é uma cidade de segregação, setorizada, moldada para privilegiar carros e com o seu centro localizado a distâncias consideráveis das periferias, dificultando o acesso de diversos grupos sociais à cidade. Apesar de grande parte da população das cidades que circundam a capital dirigir-se a Brasília diariamente para trabalhar, estudar, buscar lazer, o acesso à cidade é restringido, seja pela distância geográfica ou pela ineficiência e alto preço do transporte público da região. Como evidenciam Gatti e Pereira (2011, p. 15), Brasília é "uma cidade funcional, na qual a instrumentalização do espaço, a estabilidade e a ordem são os fins a serem obtidos a qualquer custo, via qualquer meio".

Apesar da diversidade de motivos que conduzem pessoas à situação de rua - fatores estruturais, biográficos, desastres naturais (SILVA, 2006) -, grande parte das matérias publicadas no Correioweb no corpus representa de forma superficial a questão social da situação de rua. O grande problema retratado não é que pessoas vivam em condições de extrema pobreza e cotidianamente tenham seus direitos básicos negados, mas, sim, os 'transtornos' que causam no espaço urbano (RAMALHO, 2017).

Em etapa anterior da pesquisa de que aqui apresentamos recorte, as análises apontaram que moradores/as e trabalhadores/as locais são os atores que mais avaliam pessoas em situação de rua no corpus quando se trata de tematizar a violência (em RESENDE, 2016 e em RESENDE; RAMALHO, 2017, já foram discutidos alguns resultados da etapa inicial da pesquisa); isso significa que as perspectivas de pessoas alheias à situação de rua são propagadas recorrentemente por essa mídia. Contrariamente, a voz da população em situação de rua é localizada normalmente em temas menos recorrentes no jornal, como, por exemplo, em textos que traçam 'histórias heroicas' e romantizadas de pessoas que superaram a situação de rua, reforçando questionáveis valores meritocráticos. Essa perspectiva midiática de difusão de visões das classes privilegiadas economicamente pode favorecer a dispersão de ideologias.

${ }^{2}$ Disponível em: < cidades.ibge.gov.br/brasil/df/brasilia/panorama> $>$. Acesso em: 5 mar. 2018. 
Na temática da violência, apenas um texto apresenta o que levou uma pessoa em situação de rua a tal condição. Trata-se de uma matéria relacionada ao caso de Edvan Lima (ver contextualização do caso a seguir) que traz o seguinte trecho: "Pessoas ouvidas pela reportagem contaram ter ouvido do próprio [Edvan Lima da] Silva a história de que ele passou a viver nas ruas após ter sido despejado de um barraco que construiu e ocupou por muito tempo, em uma área pública próxima à praça. Segundo essas pessoas, sem família no Distrito Federal e sem ter para onde ir, Silva passou então a viver no local onde foi atacado". ${ }^{3}$ O foco do estudo de caso aqui apresentado justifica-se, porque as matérias relacionadas a Edvan Lima apresentam características discursivas bem particulares, se comparadas às outras notícias e reportagens do corpus de 166 textos do Correioweb.

Tratar pessoas em situação de rua como inerentes ao espaço urbano e seus corpos como algo externo e desumanizado, sem uma reflexão sobre as condições que as levaram até ali, pode causar um efeito de naturalização que mascara o problema e assim restringe políticas públicas eficientes, além de legitimar a violência praticada contra esse grupo. Esse efeito, quando difundido pelo jornalismo on-line, adquire um potencial ainda maior, se levarmos em consideração que, em 2016, 94,2 milhões de brasileiros/as, ou 55\% da população, tiveram acesso a esse meio de comunicação, de acordo com o Panorama setorial da Internet. ${ }^{4}$ Esse número cresce a cada dia segundo os boletins publicados pelo Centro Regional de Estudos para o Desenvolvimento da Sociedade da Informação (Cetic.br), que acompanha há onze anos o acesso à internet no Brasil.

\section{O CASO EDVAN LIMA}

Edvan Lima estava em situação de rua e na madrugada do dia $1^{\circ}$ de agosto de 2013 foi brutalmente atacado enquanto dormia em uma praça do Guará I, ${ }^{5}$ cidade satélite de Brasília. Edvan estava com outras pessoas em situação de rua, em torno de uma fogueira para se aquecer do frio, quando um grupo de três indivíduos passou por eles, ateou gasolina e riscou um fósforo. A primeira linha de investigação suspeitou que a ação tivesse sido motivada por uma suposta briga entre pessoas em situação de rua de grupos rivais, o que chegou a ser noticiado no Correioweb, mas, posteriormente, a investigação concluiu que o crime foi premeditado e cometido pela filha de um policial federal, então com 17 anos, outro adolescente e Wesley Lima da Silva, único maior envolvido.

Os companheiros de Edvan que testemunharam e também foram vítimas do crime relataram que conseguiram fugir porque estavam acordados no momento

3 Disponível em: <www.correiobraziliense.com.br/app/noticia/cidades/2013/08/04/interna cidadesdf,380644/moradores-de-rua-do-guara-temem-retorno-de-agressores.shtml $>$. Acesso em: $1 \overline{\overline{2}}$ maio 2017.

${ }^{4}$ Disponível em: <www.nic.br/media/docs/publicacoes/6/Panorama_Setorial_11.pdf $>$. Acesso em: 25 maio 2017.

${ }^{5}$ Região Administrativa X do Distrito Federal, a cidade satélite do Guará foi fundada em abril de 1969 e tem 132.685 habitantes segundo a Pesquisa Distrital por Amostra de Domicílios 2015/2016 da Companhia de Planejamento do Distrito Federal, CODEPLAN. 
do ocorrido e, ainda assim, foram perseguidos pelos/a agressores/a. Edvan estava dormindo e não se salvou.

O caso teve repercussão e causou comoção social pela brutalidade do crime, sendo feitas referências ao nome de Edvan em 42,8\% dos textos sobre violência publicados no Correioweb no ano de 2013 (15/35). Nesse contexto, diferente de outras matérias do corpus, Edvan e as pessoas em situação de rua que estavam com ele no momento do crime são vistas de forma positiva e elogiadas por moradores/ as e comerciantes da região: "Eles são tranquilos, não mexem com ninguém. Está vendo esta praça neste estado, precisando de reparos, de ser limpa? Pois só não está pior porque eles ajudam a cuidar dela"; "Ele era muito tranquilo"; "Todo mundo aqui gostava dele e muitos já o conheciam quando ele ainda tinha um barraco lá pra baixo".

O caso estudado aqui não foi o único encontrado no corpus em que a violência contra pessoas em situação de rua partiu de moradores/as e/ou trabalhadores/as locais utilizando fogo como instrumento de ataque. Além de Edvan Lima, o caso de Paulo Cézar Maia e José Miclos de Freitas, que foram queimados enquanto dormiam próximo a uma padaria na cidade satélite de Santa Maria ${ }^{6}$ na noite de 25 de fevereiro de 2012, também foi noticiado. ${ }^{7}$ As investigações apontaram que sete pessoas teriam envolvimento com o crime, dois adolescentes além de Daniel Douglas Cavalcante Cardoso, Lucas Júnior Araújo e Sá, Edmar Pereira da Cunha Júnior, Gervanio Balbino de Oliveira e o comerciante Daniel de Abreu Lima, apontado como mandante do crime, que estaria 'incomodado' com a presença das vítimas na região por considerar que eles atrapalhavam seu negócio. ${ }^{8}$ Paulo Cézar, assim como Edvan, não sobreviveu ao ataque.

A violência descrita aqui infelizmente é parte emblemática da história da capital federal desde o assassinato do indígena Galdino Jesus dos Santos, da etnia Pataxó-hã-hã-hãe, que foi atacado com gasolina e fósforo enquanto dormia em um ponto de ônibus de Brasília em 20 de abril de 1997 e foi assim assassinado. A presença dele na região ocorreu devido às comemorações do assim chamado 'Dia do Índio', ocasião em que Galdino e outras lideranças indígenas reivindicaram ações relacionadas à Terra Indígena Caramuru-Paraguaçu, onde ocorria conflito fundiário entre indígenas e fazendeiros. Além da brutalidade do assassinato, outra ação dos agressores chamou a atenção para o caso: no julgamento, realizado quatro anos depois, em 2001, os responsáveis pelo crime - todos de classe média alta - Max Rogério Alves, Antonio Novely Villanova, Tomás Oliveira de Almeida, Eron Chaves Oliveira e Gutenber Nader Almeida Júnior - menor à época do crime - alegaram em suas defesas que queriam fazer uma brincadeira, acreditando que

${ }^{6}$ Região Administrativa XIII do Distrito Federal, a cidade satélite de Santa Maria foi fundada em fevereiro de 1990 e tem 125.123 habitantes segundo a Pesquisa Distrital por Amostra de Domicílios 2015/2016 da Companhia de Planejamento do Distrito Federal, CODEPLAN.

7 Disponível em: <www.correiobraziliense.com.br/app/noticia/cidades/2012/02/27/interna cidadesdf,291211/gasolina-pode-ter-sido-usada-para-queimar-moradores-de-rua-em-santa-maria.

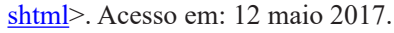

8 Disponível em: <www.correiobraziliense.com.br/app/noticia/cidades/2012/03/06/interna cidadesdf,292169/delacao-premiada-ajudou-policia-a-prender-suspeitos-de-queimarem-mendigos. shtml>. Acesso em: 12 maio 2017. 
sua vítima seria uma pessoa em situação de rua. Na época do crime, os agressores não prestaram nenhum tipo de socorro à vítima e só puderam ser identificados porque uma testemunha conseguiu anotar a placa do carro em que estavam e, posteriormente, entregou a informação às autoridades.

Os três casos brevemente apresentados aqui têm alguns pontos em comum: pessoas dormindo na rua foram atacadas sem a menor chance de defesa; os três crimes foram premeditados por pessoas alheias à vida nas ruas e as motivações estão intrinsicamente ligadas às condições sociais em que as vítimas encontravamse. Esses crimes refletem o desejo de parte da sociedade em provocar o extermínio de pessoas em situação de rua. Não é levada em consideração a estrutura social que marginaliza grupos sociais, pois os próprios grupos são vistos como o problema a ser 'atacado'. São os corpos que incomodam e podem ser aniquilados.

Considerando os estudos da corporeidade de David Le Breton (2011, 2017), aliados à abordagem teórica da análise de discurso crítica, na próxima seção discutiremos a representação verbal dos corpos de pessoas em situação de rua. ${ }^{9}$

\section{ANÁLISE DE DISCURSO CRÍTICA E CORPOREIDADE NA INVESTIGAÇÃO DA VIOLÊNCIA CONTRA PESSOAS EM SITUAÇÃO DE RUA}

Na perspectiva abordada aqui, as reflexões sobre corporeidade serão atreladas ao arcabouço teórico-metodológico da análise de discurso crítica para compreender como é representado, em reportagens e notícias retiradas do Correioweb no ano de 2013, o corpo de Edvan Lima. Nesse cenário, os textos jornalísticos serão considerados como eventos discursivos que trazem traços das práticas sociais e nos fornecem indícios para a investigação dessas mesmas práticas (VIEIRA; RESENDE, 2016).

Para Le Breton (2017), o conceito de corporeidade e as relações que os seres humanos traçam com o corpo estão ligados às transformações sociais. De acordo com estudos do antropólogo, em tempos passados o corpo era visto como unidade intangível que por si só identificava sujeitos. Atualmente, o corpo nas sociedades urbanizadas ocidentais é tido majoritariamente como algo imperfeito, passível de modificações e construções pelo próprio indivíduo (LE BRETON, 2017), que ativamente trabalha para a construção de sua subjetividade corporificada.

\footnotetext{
${ }^{9}$ No escopo da pesquisa de que este artigo é recorte, também foram analisadas as fotografias que acompanham notícias coletadas nos três veículos estudados - Correio Braziliense, O Globo e Folha de S. Paulo. Os resultados das análises de imagens apontam estratégias de distanciamento: ausência ou obscurecimento da pessoa, representada algumas vezes de forma metafórica, ou sua representação distante, de costas; fotografias tomadas em ângulo horizontal oblíquo e vertical elevado, em plano geral. As imagens enviadas, assim, reforçam o distanciamento. Quando pessoas em situação de rua são postas em saliência nas imagens, se constroem corpos conceituais, em que o padrão representacional fortalece sentidos de distanciamento e atomização; corpos deitados que sugerem inatividade; corposgrupo que criam um efeito de ameaça ou risco, sendo corpos quase condensados, voltados para si mesmos, um reforço de sentidos de desconexão (RESENDE; GOMES, 2018).
} 
Se em sociedades baseadas em estruturas diferentes da nossa o corpo pode ser concebido como algo inerente à natureza biológica do mundo, inclusive com designações semânticas comuns para denominar traços humanos e de plantas, ou, ainda, pode ser considerado na medida de suas relações com a coletividade de que faz parte (LE BRETON, 2011), no modelo urbanizado de vida isso se perde, pois aqui o corpo assume um caráter individualizado, anatomizado, dissociado da pessoa em "uma espécie de divisão ontológica" (LE BRETON, 2011, p. 350). Um exemplo disso, segundo o mesmo autor, é o fato de a cura, para alguns povos, ser vista como uma unidade, enquanto na medicina moderna o foco é tratar especificamente do corpo de forma fragmentada, e não do ser humano em sua plenitude.

O corpo nas sociedades ocidentais atuais também assume uma espécie de metamorfose, constantemente incentivada pelo mercado, pela indústria da beleza, pela mídia e por outros mecanismos de coerção social (LE BRETON, 2017). E, já que o corpo só projeta uma identidade na medida em que é personalizado, pode ser perfeitamente dispensado quando não atende aos requisitos da assim chamada modernidade. A população em situação de rua está entre os grupos que não atendem esses requisitos da modernidade-colonialidade: para essa população, "não só a pobreza, mas também a proximidade da morte - na miséria, falta de reconhecimento, linchamento e prisão - caracterizam a situação do damné", o "condenado da terra" (FANON, [1961] 2015), que Wacquant (2001) recontextualiza para falar do "condenado da cidade". O damné, assim, existe na zona do não-ser, e tendo sua humanidade questionada, passa a não ter direito a ter direitos.

O baixo grau de humanidade atribuído a certas identidades é que define a negação ontológica de que nos fala Fanon (2015), a sub-alteridade. É preciso, então, agregar aos sentidos levantados por Le Breton na sociologia do corpo uma reflexão sobre os corpos torturáveis: aqueles a serem disciplinados, dominados, domesticados, castigados (BENEDITO, 2017). Esses corpos são também os corpos de pessoas em situação de rua, que, perdendo sua condição de humanidade "nos olhos do grupo dominante" (MALDONADO-TORRES, 2007, p. 257), podem ser deixados ao relento, podem ser violentados (RESENDE, 2017b).

Focalizando o corpus aqui estudado, nos chama a atenção a representação fragmentada de Edvan Lima, exemplificando a corporeidade contemporânea anteriormente abordada. Edvan, nessa perspectiva, não é uma pessoa que foi brutalmente assassinada, é um corpo $63 \%$ queimado $;{ }^{10}$ um corpo aproximadamente $65 \%$ queimado; um corpo que sofreu queimaduras no peito, no braço esquerdo e na cabeça; que teve queimaduras de terceiro grau, em textos que trazem informações a respeito do crime, da investigação e de seu estado de saúde e, posteriormente,

10 Disponível em: <www.correiobraziliense.com.br/app/noticia/cidades/2013/08/01/interna cidadesdf,380092/homens-ateiam-fogo-em-morador-de-rua-vitima-fica-com-63-do-corpo-queimado. shtml>. Acesso em: 12 maio 2017. 
transforma-se em um corpo funerário a ser reclamado, ${ }^{11}$ retirado, ${ }^{12}$ liberado do IML e sepultado. ${ }^{13}$

Quando um corpo foge dos parâmetros propagados pela publicidade ou pela mídia, quando se encontra fora do padrão considerado ideal, há o estranhamento que provoca a não identificação com o 'outro', ou, como propõe Le Breton (2011, p. 213), "a impossibilidade de nos identificarmos fisicamente com ele (...) está na fonte de todos os preconceitos que um ator social pode sofrer".

Sendo assim, a representação fragmentada que desassocia Edvan (e outras pessoas em situação de rua) como ser humano de seu corpo, quando difundida por jornais - considerando meios de comunicação como aparato ideológico do Estado (MANIGLO, 2016) -, pode reforçar ideologias e hegemonias vigentes, quando só é considerado um 'outro' quem atende aos requisitos identitários da atualidade.

$\mathrm{O}$ conceito de ideologia em ADC é dotado de teor intrinsicamente negativo, pois é um instrumento semiótico que garante a manutenção temporária de uma representação particular de mundo (VIEIRA; RESENDE, 2016). Já o conceito de hegemonia refere-se ao "poder sobre a sociedade como um todo de uma das classes economicamente definidas como fundamentais em alianças com outras forças sociais" (FAIRCLOUGH, 2001, p. 122). Ambos os conceitos são de caráter temporário, pois, apesar de serem reforçados por estruturas sociais interessadas na manutenção do status quo, também são passíveis de transformação. O potencial efeito da ideologia na manutenção de hegemonias pôde ser observado quando as análises apontaram que apesar de a população em situação de rua ser, sobretudo, vítima de eventos de violência noticiados no jornal, e, portanto, referida majoritariamente pelo item lexical 'vítima', é avaliada em maior densidade como perigosa, num paradoxo significativo (RESENDE; RAMALHO, 2017). Quando se nega uma máscara humana a um ser humano, nos conta Zaffaroni (2007), cabe-lhe a máscara de inimigo, o que atualmente se realiza pela apropriação dos discursos de periculosidade.

Se, conforme Le Breton (2017), uma pessoa deve acrescentar uma marca própria em seu corpo para ser considerada, a população em situação de rua, sendo a parte mais frágil e vulnerável da extrema pobreza, não possui meios para atender a esses requisitos da colonial-modernidade, pois é marginalizada dos ideais contemporâneos fortemente divulgados pelas forças sociais dominantes. Por estar alijada do processo de construção identitária de reconhecimento como um 'outro', frequentemente é vista e retratada de forma desumanizada. Aqui, o corpo "já não é inteiramente o homem ( $s i c$.), na medida em que são legítimos sobre ele procedimentos que seriam socialmente percebidos como inaceitáveis se

11 Disponível em: <www.correiobraziliense.com.br/app/noticia/cidades/2013/09/02/interna cidadesdf,385747/morador-de-rua-queimado-vivo-deve-ter-enterro-social.shtml $>$. Acesso em: $12 \mathrm{de}$ maio de 2017.

12 Disponível em: <www.correiobraziliense.com.br/app/noticia/cidades/2013/09/06/interna cidadesdf,386616/morador-de-rua-queimado-vivo-no-guara-pode-ser-enterrado-como-indigente. shtml $>$. Acesso em: 12 maio 2017.

13 Disponível em: <www.correiobraziliense.com.br/app/noticia/cidades/2013/09/09/interna cidadesdf,387082/pericia-identifica-morador-de-rua-que-morreu-queimado-no-guara.shtml $>$. Acesso em: 12 maio 2017. 
concernissem ao homem (sic.) e não a um corpo dissociado" (LE BRETON, 2011, p. 356).

Assim, corpo neste trabalho será uma categoria analítica considerada na análise dos dados que tratam da representação de Edvan Lima no Correioweb, associada ao arcabouço teórico-metodológico da ADC, que contribui para a investigação de problemas sociais discursivamente manifestos, adotando como essencial a concepção de que discursos e práticas sociais estão dialeticamente interligados.

Para a ADC, o termo discurso abrange dois significados. De forma mais abstrata, é associado ao uso da linguagem em uma prática social particular, já de forma mais concreta, caracteriza um modo específico de representação de experiências no mundo, ligado a campos sociais particulares (VIEIRA; RESENDE, 2016). Para compreendermos melhor essas duas acepções e sanar a ambiguidade de termos, remetemos aqui a distinção feita por Resende (2017a), inspirada em Foucault, em que o sentido mais abstrato é chamado 'ordens de discurso', constituindo-se como um dos componentes articuladores do estrato potencial do funcionamento da linguagem, ou seja, as ordens de discurso possibilitam e controlam a ação discursiva por meio das limitações e dos potenciais que engendram em articulação com outros elementos potenciais de uma prática particular: espaço-tempo potencial, materiais potenciais, posições objetivas etc. A ordem de discurso da mídia, por exemplo, ocorre em um determinado espaçotempo, necessitando de materiais específicos dependendo de um contexto, pressupondo posições determinadas a alguns sujeitos e estabelecendo relações sociais específicas. Portanto, se "toda prática social inclui uma ordenação do aparato semiótico estruturante dos usos da linguagem na prática" (RESENDE, 2017a, p. 30), essa denominação para designar o uso da linguagem em uma prática social particular é perfeitamente adequada.

Por outro lado, falar de discursos de uma forma concreta significa compreender que há maneiras específicas de representar, de agir e interagir e de identificarmos o mundo, as pessoas e a nós mesmos (VIEIRA; RESENDE, 2016). Ao referenciar pessoas em situação de rua através de itens lexicais como, por exemplo, 'moradores/as de rua', 'mendigos/as', 'invasores/as', 'necessitados/as', 'pedintes', 'população vulnerável', 'sem-teto', 'desabrigados/as', 'suspeitos/as', 'grupo', 'indigentes' ou 'pessoas que estão nas ruas' em textos, estamos fornecendo um acesso empírico que indica a forma como reagimos à situação de rua e sobre a nossa própria perspectiva de mundo. Quando discursos específicos são difundidos como universais, contribuem para a propagação de práticas hegemônicas, o que não contempla setores da sociedade marginalizados dentro da lógica do sistema capitalista.

Investigar como ocorre a representação de pessoas em situação de rua em casos de extrema violência na mídia pode contribuir para a compreensão das práticas sociais representadas nesse contexto. 


\section{REPRESENTAÇÃO DE EDVAN LIMA NO CORREIOWEB}

De forma mais ampla, o projeto Representação midiática da violação de direitos e da violência contra pessoas em situação de rua no jornalismo on-line trabalhou com dados coletados dos portais de três mídias jornalísticas de referência no Brasil, a Folha de S. Paulo (folha.uol.com.br), de São Paulo, O Globo (oglobo. globo.com), do Rio de Janeiro, e o Correio Braziliense (correioweb.com.br), de Brasília. Na primeira etapa, coletamos todos os textos publicados nos portais dos respectivos jornais que apresentaram resultados na busca de palavras-chave associadas à situação de rua no intervalo de 2011 a 2013 (no total, 752 textos). Aqui, tratamos exclusivamente dados coletados no Correioweb.

Da coleta no Correioweb, resultaram 166 textos passíveis de codificação no software NVivo, que foram organizados em pastas temáticas, sendo 95 deles localizados na temática da violência, $32 \mathrm{em}$ políticas públicas, 18 em violação de direitos, $18 \mathrm{em}$ outros temas (por exemplo, histórias heroicas ou histórias consideradas inusitadas envolvendo pessoas em situação de rua) e três em drogas. Posteriormente, os dados foram codificados em categorias de preparação e análise utilizando recursos proporcionados pelo NVivo. As categorias de análise foram teoricamente motivadas pela análise de discurso crítica; assim, foi possível a realização de uma macro análise que está descrita de forma detalhada em trabalhos anteriores (ver RESENDE, 2016 e RESENDE; RAMALHO, 2017).

Entre várias perguntas que dirigimos aos dados com o suporte do software, apropriando-nos da ferramenta de matriz de codificação, estava a seguinte: como pessoas em situação de rua são avaliadas por vozes externas à voz autoral em textos com a temática da violência? A seguir, está a tabela que responde a essa questão, contendo as avaliações e a quantidade de vezes que elas ocorrem.

\begin{tabular}{|c|c|}
\hline $\begin{array}{c}\text { AVALIAC̄̃O/ } \\
\text { INTERTEXTUUALIDADE }\end{array}$ & $\begin{array}{l}\text { RECORRÊNCIAS EM } \\
\text { VIOLẾNCIA }\end{array}$ \\
\hline Agressivas & 4 \\
\hline Boas & 1 \\
\hline Discriminadas & 3 \\
\hline Incômodas & 16 \\
\hline Oportunistas & 2 \\
\hline Perigosas & 69 \\
\hline Queridas & 1 \\
\hline Trabalhadoras & 2 \\
\hline Tranquilas & 3 \\
\hline Viciadas & 9 \\
\hline Violentas & 2 \\
\hline
\end{tabular}

Tabela 1 - Modos de avaliação de pessoas em situação de rua por vozes externas na temática da violência e suas recorrências em textos publicados no Correioweb entre os anos de 2011 e 2013

É importante ressaltar aqui que há outros modos de avaliação de pessoas em situação de rua no corpus, mas apenas esses são evocados em instâncias de articulação intertextual de vozes externas à voz autoral. Outros estão situados na voz autoral do jornal e por esse motivo não apareceram neste cruzamento dos 
dados, pois optamos por investigar, neste momento, apenas as vozes externas ao jornal que são convocadas a falar e avaliar pessoas em situação de rua nesse contexto: as vozes de ativistas e religiosos, de coletivos de pessoas em situação de rua, de empresários, de entidades escolares, de familiares de pessoas em situação de rua, de moradores/as e trabalhadores/as locais, de outras pessoas que aparecem sem uma classificação particular recorrente, de pessoas em situação de rua, da polícia, de testemunhas, de representantes da lei, de especialistas, do governo e de representantes de vozes médicas. Todas essas vozes foram codificadas de acordo com suas aparições nos textos, pois o processo de codificação dos dados é feito manualmente no software, o que significa a necessidade de leitura de todas as reportagens e notícias coletadas nos portais antes da realização das codificações e posteriores matrizes de codificação.

Além de nos atermos aos qualificadores negativos que mais aparecem na Tabela 1, "perigosas" (69), "incômodas" (16) e "viciadas" (9) - qualificadores que percorrem todas as outras temáticas não só do corpus do Correio Braziliense, mas também dos outros dois jornais investigados no âmbito do projeto integrado -, consideramos necessário voltar-nos para as exceções, e olhar de forma mais atenta os qualificadores positivos que aparecem nos dados: "tranquilas" (3), "trabalhadoras" (2), "boas" (1) e "queridas" (1). Com a observação mais detalhada, percebemos que essas avaliações são praticamente restritas ao caso de Edvan Lima.

Também utilizamos a ferramenta de pesquisa de palavras, proporcionada pelo software, e procuramos por "Ed*van" (o uso de asterisco foi necessário porque ora seu nome aparece como Edvan e ora, como Edivan) para chegar aos textos específicos que o citam. Dos 35 textos tematizando violência no ano de 2013, 15 referem-se a ele em algum momento, ou seja, 42,8\% dos textos situados na temática de violência naquele ano fazem, em algum momento, menção ao brutal crime cometido contra Edvan Lima, índice bastante significativo. Por isso, delimitamos o foco para esta micro análise.

Considerando os 15 textos que mencionam Edvan Lima, constatamos que cinco deles não são focados no caso específico, mas o citam no contexto de outros assuntos da temática de violência, e, portanto, não serão foco de análise neste artigo. Assim, dez textos do corpus inicial de 166 passaram pela micro análise neste trabalho.

As manchetes dos textos que tratam de forma particular do caso de Edvan Lima podem ser observadas no quadro a seguir, que nos fornece também a visualização de suas datas de publicação, informações sobre autoria - texto assinado ou não? - e o Caderno onde foi publicado no jornal: 


\begin{tabular}{|c|c|c|c|}
\hline MANCHETE & DATA & AUTORIA & CADERNO \\
\hline $\begin{array}{l}\text { Homens ateiam fogo } \\
\text { em morador de rua; } \\
\text { vítima fica com } 63 \% \\
\text { do corpo queimado }\end{array}$ & 1 de agosto de 2013 & Não assinado & Cidades \\
\hline $\begin{array}{c}\text { Rixa entre grupos rivais } \\
\text { pode ter motivado } \\
\text { incêndio em moradores } \\
\text { de rua }\end{array}$ & 1 de agosto de 2013 & Não assinado & Cidades \\
\hline $\begin{array}{c}\text { Morador de rua } \\
\text { queimado no Guará } \\
\text { continua em estado } \\
\text { grave }\end{array}$ & 3 de agosto de 2013 & Não assinado & Cidades \\
\hline $\begin{array}{l}\text { Moradores de rua do } \\
\text { Guará temem retorno } \\
\text { de agressores }\end{array}$ & 4 de agosto de 2013 & Não assinado & Cidades \\
\hline $\begin{array}{c}\text { Polícia detém suspeitos } \\
\text { de atear fogo e matar } \\
\text { morador de rua no } \\
\text { Guará }\end{array}$ & 20 de agosto de 2013 & $\begin{array}{l}\text { Saulo Araújo } \\
\text { Kelly Almeida } \\
\text { Ariadne Sakkis }\end{array}$ & Cidades \\
\hline $\begin{array}{l}\text { Trio que matou } \\
\text { morador de rua } \\
\text { queimado não teria } \\
\text { mostrado } \\
\text { arrependimento }\end{array}$ & 21 de agosto de 2013 & $\begin{array}{l}\text { Kelly Almeida } \\
\text { Saulo Araújo }\end{array}$ & Cidades \\
\hline $\begin{array}{l}\text { Ativistas se reúnem } \\
\text { para homenagear } \\
\text { morador de rua } \\
\text { queimado no Guará }\end{array}$ & 23 de agosto de 2013 & Sheila Oliveira & Cidades \\
\hline $\begin{array}{l}\text { Morador de rua } \\
\text { queimado vivo deve ter } \\
\text { enterro social }\end{array}$ & 2 de setembro de 2013 & Larissa Garcia & Cidades \\
\hline $\begin{array}{l}\text { Morador de rua } \\
\text { queimado vivo no } \\
\text { Guará pode ser } \\
\text { enterrado como } \\
\text { indigente }\end{array}$ & 6 de setembro de 2013 & Kelly Almeida & Cidades \\
\hline $\begin{array}{c}\text { Perícia identifica } \\
\text { morador de rua que } \\
\text { morreu queimado no } \\
\text { Guará }\end{array}$ & 9 de setembro de 2013 & $\begin{array}{l}\text { Kelly Almeida } \\
\text { Thais Paranhos }\end{array}$ & Cidades \\
\hline
\end{tabular}

Quadro 1 - Manchetes dos textos sobre o caso de Edvan Lima

Como mostra o quadro, todos os textos sobre o caso Edvan Lima estão situados no Caderno Cidades, seção do jornal que aborda fatos cotidianos e que cumpre também o papel de caderno policial. As matérias sobre o caso não são assinadas até 4 de agosto, situação que muda a partir do dia 20 , quando se descobriu que os assassinos de Edvan Lima não eram pessoas em situação de rua. Assim, o caso adquire maior relevância quando se descola do âmbito da situação de rua, passando a incluir outro grupo social.

Em um primeiro momento, é notável que, apesar de o nome de Edvan Lima ser recorrente nos textos de violência do ano de 2013, em nenhuma das manchetes seu nome é citado. Em oito textos que evidenciam por meio da manchete o crime cometido contra ele, Edvan Lima é representado como "morador de rua" ("Homens 
ateiam fogo em morador de rua"; 14 "Morador de rua queimado no Guará continua em estado grave"; 15 "Polícia detém suspeitos de atear fogo e matar morador de rua"; 16 "Trio que matou morador de rua",17 "Ativistas se reúnem para homenagear morador de rua queimado"18 e "Perícia identifica morador de rua que morreu queimado"19), quando só podemos perceber sua especificidade pela colocação do termo no singular, mas sem individualização pelo uso de seu nome. Além disso, o termo 'morador de rua' reflete uma contradição e naturalização dessa situação de extrema vulnerabilidade, pois não ter moradia adequada é justamente o que caracteriza e marginaliza essa população.

Já nas manchetes dos outros dois textos acerca do caso, Edvan Lima é retratado como participante de uma coletividade, de um grupo; ora para apresentar suposições sobre a motivação do assassinato (que depois se provaram falsas): "Rixa entre grupos rivais pode ter motivado incêndio em moradores de rua", ${ }^{20}$ ora para retratar uma consequência da brutalidade: "Moradores de rua do Guará temem retorno de agressores" ${ }^{21}$ No primeiro caso, a manchete sugere que o grupo de que Edvan fazia parte e a população em situação de rua em geral não seriam pacíicos, pois, se fossem, não estariam envolvidos em 'rixa'; mas, no segundo caso, são representados temendo novas agressões, e o termo 'agressores' já não é direcionado a outras pessoas em condições de semelhante vulnerabilidade e, pela manchete, já não podemos presumir os criminosos, os grupos sociais aos quais pertencem, suas condições socioeconômicas, de gênero ou nenhuma outra informação.

Ao considerar as ampliações de manchetes, quando é o caso, em busca da individualização de Edvan Lima, há uma exceção que pode ser observada a seguir:

14 Disponível em: <www.correiobraziliense.com.br/app/noticia/cidades/2013/08/01/interna cidadesdf,380092/homens-ateiam-fogo-em-morador-de-rua-vitima-fica-com-63-do-corpo-queimado.

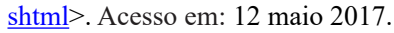

15 Disponível em: <www.correiobraziliense.com.br/app/noticia/cidades/2013/08/03/interna cidadesdf,380547/morador-de-rua-queimado-no-guara-continua-em-estado-grave.shtml $>$. Acesso em: 12 maio 2017.

16 Disponível em: <www.correiobraziliense.com.br/app/noticia/cidades/2013/08/20/interna cidadesdf,383487/policia-detem-suspeitos-de-atear-fogo-e-matar-morador-de-rua-no-guara.shtml $>$. Acesso em: 12 maio 2017.

17 Disponível em: <www.correiobraziliense.com.br/app/noticia/cidades/2013/08/21/interna cidadesdf,383592/trio-que-matou-morador-de-rua-queimado-nao-teria-mostrado-arrependimento. shtml>. Acesso em: 12 maio 2017.

18 Disponível em: <www.correiobraziliense.com.br/app/noticia/cidades/2013/08/23/interna cidadesdf,384189/ativistas-se-reunem-para-homenagear-morador-de-rua-queimado-no-guara.shtml $>$. Acesso em: 12 maio 2017.

19 Disponível em: <www.correiobraziliense.com.br/app/noticia/cidades/2013/09/09/interna cidadesdf,387082/pericia-identifica-morador-de-rua-que-morreu-queimado-no-guara.shtml $>$. Acesso em: 12 maio 2017.

${ }_{20}$ Disponível em: <www.correiobraziliense.com.br/app/noticia/cidades/2013/08/01/interna cidadesdf,380147/rixa-entre-grupos-rivais-pode-ter-motivado-incendio-em-moradores-de-rua.shtml> . Acesso em: 12 maio 2017.

${ }_{21}$ Disponível em: <www.correiobraziliense.com.br/app/noticia/cidades/2013/08/04/interna cidadesdf,380644/moradores-de-rua-do-guara-temem-retorno-de-agressores.shtml>. Acesso em: 12 maio 2017. 


\section{Ativistas se reúnem para homenagear morador de rua queimado no Guará}

Edvan Lima da Silva, de 49 anos, morreu no início

do mês após ser queimado por três jovens

Figura 1. Manchete de texto sobre Edvan Lima do dia 23 de agosto de 2013

Fonte: Correioweb

Essa é a única ampliação de manchete que retrata Edvan Lima não apenas como uma pessoa em situação de rua, mas como alguém que tem nome e idade, informações mínimas, se levarmos em consideração o padrão jornalístico. Curiosamente, é nessa reportagem que moradores/as locais referenciados/as como 'ativistas' pelo jornal cobram justiça ao caso e políticas públicas governamentais que atendam as pessoas em situação de rua. De modo geral, a representação de Edvan nas manchetes não se atém a seus traços identificacionais mais específicos.

$\mathrm{Na}$ segunda manchete apresentada no Quadro 1, publicada no dia 1 de agosto de 2013, dia em que o caso de Edvan Lima começa a ser noticiado no jornal, destacamos a construção "incêndio em moradores de rua" por ser uma colocação não usual na língua: se considerarmos os itens lexicais que geralmente sucedem o substantivo "incêndio" indicando local de propagação de fogo, é incomum a presença de atores humanos - esse aspecto já foi destacado por Resende e Gomes (2018). Em uma rápida busca no Correioweb por "incêndio em', têm-se como resultado "incêndio em supermercado", "incêndio em prédio", "incêndio em Samambaia", "incêndio em escola", "incêndio em apartamento", "incêndio em barraco", entre outros. Se ampliarmos ainda mais a pesquisa e colocarmos a construção 'incêndio em' no Google, encontramos, além das construções observadas no Correioweb, "incêndio em reserva florestal", "incêndio em garagem", "incêndio em restaurante", "incêndio em ônibus", "incêndio em condomínio", entre outros que reproduzem o padrão "incêndio em + circunstância locativa', confirmando o uso incomum encontrado na manchete em análise. Assim, nessa construção, pessoas em situação de rua estão em uma colocação atípica para atores humanos, ou seja, estão sendo, na gramática da colocação, desumanizadas e objetificadas: postas na zona do não ser.

Com indícios do apagamento identitário desse ator social e de sua desumanização, foi necessário investigar de forma mais atenta os trechos 
específicos das reportagens que caracterizam Edvan Lima. Esse mapeamento pode ser observado no quadro a seguir, que contém as informações de data, manchete e os respectivos trechos que o representam em cada texto.

\begin{tabular}{|c|c|c|}
\hline DATA & MANCHETE & TRECHOS \\
\hline \multirow{3}{*}{$\begin{array}{l}1 \text { de agosto } \\
\text { de } 2013\end{array}$} & \multirow{3}{*}{$\begin{array}{c}\text { Homens ateiam fogo em } \\
\text { morador de rua; vítima } \\
\text { fica com } 63 \% \text { do corpo } \\
\text { queimado. }\end{array}$} & $\begin{array}{l}\text { O morador de rua Edvan Lima, } 49 \text { anos, co- } \\
\text { nhecido como Antero pelos colegas, teve } \\
\text { aproximadamente } 65 \% \text { do corpo queimado, } \\
\text { enquanto dormia com um grupo de quatro } \\
\text { mendigos na QE } 18 \text {, no Guará I, na madrugada } \\
\text { desta quinta }\left(1^{\circ} / 8\right) \text {. }\end{array}$ \\
\hline & & $\begin{array}{l}\text { Edvan não conseguiu fugir e sofreu } \\
\text { queimaduras no peito, no braço esquerdo e na } \\
\text { cabeça. }\end{array}$ \\
\hline & & $\begin{array}{l}\text { Em nota, a Secretaria de Saúde informou que a } \\
\text { vítima está com } 63 \% \text { do corpo queimado sen- } \\
\text { do que } 27 \% \text { é queimadura de terceiro grau. }\end{array}$ \\
\hline \multirow{3}{*}{$\begin{array}{l}1 \text { de agosto } \\
\text { de } 2013\end{array}$} & \multirow{3}{*}{$\begin{array}{l}\text { Rixa entre grupos rivais } \\
\text { pode ter motivado in- } \\
\text { cêndio em moradores } \\
\text { de rua. }\end{array}$} & $\begin{array}{l}\text { Edvan Lima, } 49 \text { anos, não conseguiu fugir e } \\
\text { sofreu queimaduras no peito, no braço esquer- } \\
\text { do e na cabeça. }\end{array}$ \\
\hline & & $\begin{array}{l}\text { A Polícia Civil trabalha com duas linhas de } \\
\text { investigação do incêndio a moradores de rua, } \\
\text { que deixou uma das vítimas com } 63 \% \text { do cor- } \\
\text { po queimado, na madrugada desta quinta-feira } \\
(1 \%) \text {. }\end{array}$ \\
\hline & & $\begin{array}{l}\text { Edvan Lima, } 49 \text { anos, não conseguiu fugir e } \\
\text { sofreu queimaduras no peito, no braço esquer- } \\
\text { do e na cabeça. }\end{array}$ \\
\hline \multirow{3}{*}{$\begin{array}{l}\text { 03de agos- } \\
\text { to de } 2013\end{array}$} & \multirow{3}{*}{$\begin{array}{l}\text { Morador de rua queima- } \\
\text { do no Guará continua } \\
\text { em estado grave. }\end{array}$} & $\begin{array}{l}\text { A vítima teve } 63 \% \text { do corpo queimados, se- } \\
\text { gundo boletim médico. }\end{array}$ \\
\hline & & $\begin{array}{l}\text { O morador de rua Edivan da Lima Silva, } 48 \\
\text { anos, que teve o corpo queimado na última } \\
\text { quinta-feira }\left(1^{\circ}\right) \text {, continua internado em esta- } \\
\text { do grave, no Hospital Regional da Asa Norte } \\
\text { (Hran). }\end{array}$ \\
\hline & & $\begin{array}{l}\text { Silva teve queimaduras de terceiro grau em } \\
27 \% \text { do corpo, inclusive na região da cabeça. }\end{array}$ \\
\hline \multirow[b]{2}{*}{$\begin{array}{c}4 \text { de agosto } \\
\text { de } 2013\end{array}$} & \multirow[b]{2}{*}{$\begin{array}{l}\text { Moradores de rua do } \\
\text { Guará temem retorno de } \\
\text { agressores. }\end{array}$} & $\begin{array}{l}\text { Na última quinta-feira um morador de rua teve } \\
\text { o corpo queimado por agressores e morreu } \\
\text { neste sábado. }\end{array}$ \\
\hline & & $\begin{array}{l}\text { A notícia da morte de Edivan da Lima Silva, } \\
48 \text { anos, fez crescer o medo entre os moradores } \\
\text { de rua que costumam passar os dias na praça } \\
\text { do Guará I (DF) onde, na madrugada da última } \\
\text { quinta-feira (1), Silva teve o corpo incendiado. }\end{array}$ \\
\hline
\end{tabular}




\begin{tabular}{|c|c|c|}
\hline $\begin{array}{l}20 \text { de agos- } \\
\text { to de } 2013\end{array}$ & $\begin{array}{l}\text { Polícia detém suspeitos } \\
\text { de atear fogo e matar } \\
\text { morador de rua no } \\
\text { Guará. }\end{array}$ & $\begin{array}{l}\text { Ele teve } 63 \% \text { do corpo queimado e morreu } \\
\text { dois dias depois, no Hospital Regional da Asa } \\
\text { Norte (Hran). }\end{array}$ \\
\hline \multirow{2}{*}{$\begin{array}{l}21 \text { de agos- } \\
\text { to de } 2013\end{array}$} & \multirow{2}{*}{$\begin{array}{l}\text { Trio que matou morador } \\
\text { de rua queimado não } \\
\text { teria mostrado arrepen- } \\
\text { dimento. }\end{array}$} & $\begin{array}{l}\text { Levado para o Hospital Regional da Asa Norte } \\
\text { (Hran), com } 63 \% \text { do corpo queimado, Edvan } \\
\text { morreu dois dias depois. }\end{array}$ \\
\hline & & $\begin{array}{l}\text { Eles confessaram ter queimado vivo Edvan } \\
\text { Lima da Silva, } 49 \text { anos, enquanto ele dormia } \\
\text { na praça da QE } 18 \text {. }\end{array}$ \\
\hline \multirow{2}{*}{$\begin{array}{l}23 \text { de agos- } \\
\text { to de } 2013\end{array}$} & \multirow{2}{*}{$\begin{array}{l}\text { Ativistas se reúnem para } \\
\text { homenagear morador de } \\
\text { rua queimado no Guará }\end{array}$} & $\begin{array}{l}\text { Edvan Lima da Silva, de } 49 \text { anos, morreu no } \\
\text { início do mês após ser queimado por três jo- } \\
\text { vens. }\end{array}$ \\
\hline & & $\begin{array}{l}\text { Um grupo de } 10 \text { moradores do Guará se reuni- } \\
\text { ram por volta das } 17 \text { h desta sexta-feira (23/8), } \\
\text { na praça pública da QE } 16 \text {, onde Edvan Lima } \\
\text { da Silva, } 49 \text { anos, foi queimado por três jovens. }\end{array}$ \\
\hline \multirow{5}{*}{$\begin{array}{l}2 \text { de se- } \\
\text { tembro de } \\
2013\end{array}$} & \multirow{5}{*}{$\begin{array}{l}\text { Morador de rua queima- } \\
\text { do vivo deve ter enterro } \\
\text { social }\end{array}$} & $\begin{array}{l}\text { O prazo para reclamar o corpo do morador } \\
\text { de rua queimado vivo, há um mês, no Guará, } \\
\text { encerrou ontem e nenhum parente de Edvan } \\
\text { Lima dos Santos, } 49 \text { anos, apareceu no Institu- } \\
\text { to de Medicina Legal (IML). }\end{array}$ \\
\hline & & $\begin{array}{l}\text { A liberação do corpo deverá ser feita pela De- } \\
\text { fensoria Pública do DF nos próximos dias. }\end{array}$ \\
\hline & & $\begin{array}{l}\text { A partir daí, será feito o agendamento com o } \\
\text { serviço funerário da Sedest, que retira o corpo } \\
\text { e o leva até o cemitério. }\end{array}$ \\
\hline & & O corpo ainda vai ficar um tempo no IML. \\
\hline & & $\begin{array}{l}\text { Edvan foi encaminhado para o Hospital Regio- } \\
\text { nal da Asa Norte (Hran) com } 63 \% \text { do corpo } \\
\text { queimado. }\end{array}$ \\
\hline \multirow[b]{2}{*}{$\begin{array}{l}6 \text { de se- } \\
\text { tembro de } \\
2013\end{array}$} & \multirow{2}{*}{$\begin{array}{l}\text { Morador de rua quei- } \\
\text { mado vivo no Guará } \\
\text { pode ser enterrado como } \\
\text { indigente }\end{array}$} & $\begin{array}{l}\text { Ele tem } 63 \% \text { do corpo queimado e morre dois } \\
\text { dias depois após paradas cardiorrespiratórias. }\end{array}$ \\
\hline & & $\begin{array}{l}\text { Identificado como Edvan Lima da Silva, o cor- } \\
\text { po da vítima foi encaminhado ao Instituto de } \\
\text { Medicina Legal (IML) em } 3 \text { de agosto. Perma- } \\
\text { nece no local até hoje }\end{array}$ \\
\hline
\end{tabular}




\begin{tabular}{|c|c|c|}
\hline \multirow{3}{*}{$\begin{array}{l}9 \text { de se- } \\
\text { tembro de } \\
2013\end{array}$} & \multirow{3}{*}{$\begin{array}{l}\text { Perícia identifica mora- } \\
\text { dor de rua que morreu } \\
\text { queimado no Guará }\end{array}$} & $\begin{array}{l}\text { O corpo está há mais de um mês no Instituto de } \\
\text { Medicina Legal (IML) e a vítima seria enterra- } \\
\text { da sem identificação, pois não foi localizado } \\
\text { qualquer documento ou parente que compro- } \\
\text { vasse o nome. }\end{array}$ \\
\hline & & $\begin{array}{l}\text { Agora, a Sedest poderá fazer o sepultamento } \\
\text { do corpo identificado. }\end{array}$ \\
\hline & & $\begin{array}{l}\text { Ele teve } 63 \% \text { do corpo queimado e morreu } \\
\text { dois dias depois. }\end{array}$ \\
\hline
\end{tabular}

Quadro 2. Trechos de textos que representam o corpo de Edvan Lima

Do dia 1 ao dia 23 de agosto de 2013, Edvan Lima é representado nos trechos de sete matérias do Correioweb principalmente de forma fragmentada: ora é representado metonimicamente por seus membros afetados pelo ato criminoso, ora é retratado possuindo um corpo, mas não como um sujeito em sua plenitude, com corpo, alma, mente ou outras dimensões corpóreas, aproximandose da dissociação contemporânea do corpo discutida por Le Breton $(2011,2017)$. Edvan é, assim, descrito como corpo "aproximadamente 65\% (...) queimado", que "sofreu queimaduras no peito, no braço esquerdo e na cabeça" (duas vezes); frequentemente representado em termos percentuais da cobertura da lesão: " $63 \%$ do corpo queimado sendo que 27\% é queimadura de terceiro grau", "teve 63\% do corpo queimado" (cinco vezes), "teve queimaduras de terceiro grau em $27 \%$ do corpo, inclusive na região da cabeça", "teve o corpo incendiado"; como corpo presente em incêndio que "deixou uma das vítimas com $63 \%$ do corpo queimado", ou como algo (objetificado, como vimos) que "teve o corpo incendiado".

As exceções nesse período são construções que ocorrem no primeiro texto, de 1 de agosto, e em duas matérias de 21 e de 23 de agosto de 2013 . No primeiro deles, a Edvan Lima é atribuído um codinome, "Antero", o que aproxima a narrativa do discurso policial: sabemos que a atribuição de codinomes a sujeitos no domínio do discurso jornalístico ocorre em referência a atores que violam as leis, que, como forma de esconderem suas identidades, são conhecidos por outros nomes. Assim, nesse trecho, embora não haja a objetificação observada antes, há uma atribuição identificacional negativa pesando na representação de Edvan Lima. No texto de 21 de agosto, aparece o trecho "Eles confessaram ter queimado vivo Edvan Lima da Silva, 49 anos, enquanto ele dormia na praça da QE 18 ", e na matéria de 23 de agosto de 2013, são encontrados os trechos "Edvan Lima da Silva, de 49 anos, morreu no início do mês após ser queimado por três jovens" e "Edvan Lima da Silva, 49 anos, foi queimado por três jovens". Nesses trechos, também é representado em sua unidade, pois é uma pessoa que foi queimada viva e não um corpo que teve partes violadas, um corpo dissociado de seu ser mental, emocional, espiritual, como ocorre na maior parte dos textos.

Posteriormente, de 2 a 9 de setembro, em três matérias, além de ser representado de modo similar aos primeiros textos sobre o caso, como corpo " $63 \%$ queimado", passa a ser representado de forma ainda mais dissociada, pois, agora, 
biologicamente não está mais vivo e torna-se corpo funerário a ser 'reclamado', 'liberado', 'retirado', 'encaminhado' e 'sepultado'.

Outra construção peculiar aparece de modo similar no corpus três vezes nos primeiros textos sobre o caso, datados do dia 1 de agosto de 2013: "Edvan Lima, 49 anos [ou simplesmente Edvan], não conseguiu fugir e sofreu queimaduras no peito, no braço esquerdo e na cabeça". Aqui, o fato de Edvan ter sido violado é ligado a sua incapacidade de fuga, gerando uma mitigação da ação violenta e criminal.

No trecho "A Polícia Civil trabalha com duas linhas de investigação do incêndio a moradores de rua, que deixou uma das vítimas com 63\% do corpo queimado", retirado de reportagem do dia 1 de agosto, há construção ("incêndio a moradores de rua") semelhante à que já foi discutida na análise das manchetes.

Nos excertos apresentados no Quadro 2, Edvan Lima é majoritariamente um objeto que sofre ações, que teve o corpo queimado, que sofreu queimaduras, que foi vítima e, depois de seu falecimento, como corpo que espera ser reclamado, retirado, encaminhado e sepultado. É curioso notar que as únicas atividades que Edvan parece exercer nos trechos do Quadro 2 são as ações de dormir com um grupo de outras pessoas em situação de rua e a ação de tentar fugir, que possui teor negativo nesse contexto, já que ele não logrou êxito. As pessoas em situação de rua que conviviam com Edvan também são retratadas como sujeitos que não exercem ações efetivas no mundo, pois, costumam passar os dias na praça do Guará I, o que nos remete a uma ideia de improdutividade negativamente marcada em sociedades capitalistas.

O combate à permanência de pessoas nas ruas já é reforçado no ordenamento jurídico brasileiro desde 3 de outubro de 1941, quando foi criado o Decreto-lei ${ }^{\circ}$ $3.688,{ }^{22}$ mais conhecido como "lei da vadiagem", que assegurava o recolhimento de pessoas em situação de rua pelo Estado, como forma de controle de população e território urbano, e considerava que os/as recolhidos/as poderiam ter suas penas extinguidas, caso comprovassem ter meios de assegurar suas subsistências. A criminalização de pessoas em situação de rua ainda é presente, e isso se reflete na forma desumanizada como Edvan é representado.

\section{CONSIDERAÇÕES FINAIS}

A representação de Edvan Lima nos dez textos do Correioweb que discorrem sobre seu assassinato por integrantes da classe média brasiliense, majoritariamente o coloca em posição de corpo-objeto ou corpo-local, de forma desumanizada, dissociada dos elementos que normalmente associamos a nossa condição humana: ação no mundo, sentimentos, pensamentos, espiritualidade. Nesse contexto, ocorre a descaracterização da individualidade de Edvan Lima, o apagamento de seus traços identitários e a representação de seu corpo em uma dissociação de seu ser.

\section{7.}

${ }^{22}$ Disponível em: <www.planalto.gov.br/ccivil_03/decreto-lei/Del3688.htm>. Acesso em: 5 jul. 
Na maioria dos textos investigados, Edvan Lima não é um 'ser' em sua plenitude, é algo que 'possui um corpo'. Além disso, Edvan e o grupo de pessoas em situação de rua que convivia com ele são representados inertes no mundo, não exercendo ações efetivas e, quando as exercem, é de forma negativa porque não logram êxito, exceto quando a ação realizada é dormir ou permanecer nas ruas. Levando em consideração os efeitos de sentidos provocados, isso pode contribuir para que essa população não seja vista como seres humanos e, sim, como objetos que fazem parte da paisagem urbana, na medida em que assumem posições textuais de elementos como 'prédio', ‘barraco' e ‘ônibus' (em colocação com incendiar, como vimos). De acordo com os estudos sobre corporeidade na contemporaneidade (LE BRETON, 2011), esse fator pode contribuir para que ações antes vistas com desprezo quando destinadas a atores humanos sejam legitimadas quando voltadas para corpos dissociados, para seres humanos ativamente produzidos como pertencentes a uma zona do não-ser.

\section{REFERENCIAS}

BRASIL. Decreto-lei no 3.688, de 3 de Outubro de 1941. Lei das contravenções penais. Disponível online em www.planalto.gov.br/ccivil 03/decreto-lei/Del3688.htm. Consulta: 5 de julho de 2017.

BENEDITO, D. Conferência no Seminário Direito em Debate. Brasília: Universidade de Brasília, 2017.

CETIC/ CGI/ UNESCO. Acesso à internet no Brasil: desafios para conectar toda a população. In: Panorama setorial da Internet. Ano 8, Número 1, 2016. Disponível em: <www.nic.br/media/ docs/publicacoes/6/Panorama_Setorial_11.pdf> $>$. Acesso em: 25 maio 2017.

FANON, F. Pele negra máscaras brancas. Trad. Renato da Silveira. Salvador: UFBA, 2015.

FAIRCLOUGH, N. Discurso e mudança social. Trad. Izabel Magalhães (Org). Brasília: Editora Universidade de Brasília, 2001.

GATTI, B. P.; PEREIRA, C. P. Projeto renovando a cidadania: pesquisa sobre a população em situação de rua do Distrito Federal. Brasília: Gráfica Executiva, 2011.

IBGE. Brasil/Distrito Federal/ Brasília. 2010. Disponível em: < cidades.ibge.gov.br/brasil/df/brasilia/ panorama $>$. Acesso em: 04 mar. 2018.

LE BRETON, D. Antropologia do corpo e modernidade. Trad. Fábio dos Santos Creder Lopes. Petrópolis: Editora Vozes, 2011.

LE BRETON, D. O paradigma da corporeidade na contemporaneidade (comunicação oral). Brasília, Universidade de Brasília, 2017. Disponível em: <neconblog.wordpress.com/2017/03/27/ confira-novamente-a-palestra-de-david-le-breton>. Acesso em: 12 de maio de 2017.

MALDONADO-TORRES, N. On the coloniality of being: contributions to the development of a concept. Cultural Studies, 21, p. 240-70, 2007. 
MANIGLO, F. Curso virtual. Como nos vendenla moto! Análisis crítico del discurso (ADC) y la utilizácion de NVivo. Quito: Ciespal, 2016.

PEREIRA, C. P. Rua sem saída. Brasília: Ícone, 2009.

RAMALHO, I.S. O caso Edvan Lima e a corporeidade de pessoas em situação de rua em casos de violência no jornal Correio Braziliense, 2017. Trabalho apresentado no XII Congresso Internacional da Associação Latino-Americana de Estudos do Discurso, Santiago do Chile, 2017.

RESENDE, V. M. Representação de pessoas em situação de rua no jornalismo on-line: quais são as vozes convocadas para falar sobre a situação de rua? Revista de Estudos da Linguagem, 26(3), 955-988, 2016. Disponível em <www.periodicos.letras.ufmg.br/index.php/relin/article/ view/10887>. Acesso em: 16 jul. 2018.

RESENDE, V. M. Análise de discurso crítica: reflexões teóricas e epistemológicas quase excessivas de uma analista obstinada, p.11-51. In: RESENDE, V. M.; REGIS, J. F. (Orgs.). Outras perspectivas em análise de discurso crítica. Campinas: Pontes, 2017a.

RESENDE, V. M. Gestão policial da pobreza: vulnerabilidade de pessoas em situação de rua aos rigores da ordem pública - um estudo do caso de Samir Ali Ahmed Sati. Revista Cis (Fundación Techo Chile), 23, p. 15-31, 2017 b.

RESENDE, V. M.; GOMES, M. C. A. Representação da situação de rua no jornalismo eletrônico em textos verbo-visuais - a violência em discurso no Correio Braziliense (2011-2013). Revista Linguagem em (Dis)curso, v.18, n.1, p. 165-191, 2018. Disponível em: $<$ http://www. portaldeperiodicos.unisul.br/index.php/Linguagem Discurso/article/view/6089/3640>. Acesso em: 16 jul. 2018.

RESENDE, V. M.; RAMALHO, I. S. Representação midiática da violação de direitos e da violência contra pessoas em situação de rua no Correio Web. Revista Calidoscópio, vol. 15, n. 3, p. 529-541, 2017. Disponível em: <revistas.unisinos.br/index.php/calidoscopio/article/view/ cld.2017.153.11>. Acesso em: 16 jul. 2018.

SILVA, M. L. L. Mudanças recentes no mundo do trabalho e do fenômeno população em situação de rua no Brasil 1995-2005. Dissertação de Mestrado (Política Social). Universidade de Brasília, 2006.

VIEIRA, V. C.; RESENDE, V. M. Análise de discurso (para a) crítica: O texto como material de pesquisa. Campinas: Pontes Editores, 2016

WACQUANT, L. As prisões da miséria. Rio de Janeiro: Jorge Zahar, 2001.

ZAFFARONI, E. R. O inimigo no Direito Penal. Rio de Janeiro: Revan, 2007. 